\title{
Controle da Requeima em Tomateiro Industrial com Fungicidas e Silicato de Potássio
}

\author{
Henrique S.S. Duarte, Laércio Zambolim \& Fabrício Á. Rodrigues \\ Departamento de Fitopatologia, Universidade Federal de Viçosa, CEP 36571-000, Viçosa, MG, e-mail: zambolim@ufv.br
}

Autor para correspondência: Laércio Zambolim

DUARTE, H.S.S., ZAMBOLIM, L. \& RODRIGUES, F.A. Controle da requeima em tomateiro industrial com fungicidas e silicato de potássio. Fitopatologia Brasileira 32:257-260. 2007.

\section{RESUMO}

O objetivo deste trabalho foi avaliar o efeito da aplicação de fungicidas e silicato de potássio, no controle da requeima (Phytophthora infestans), em tomateiro industrial. Os fungicidas foram aplicados com base no sistema de previsão de Wallin e calendário fixo de pulverizações. Empregou-se o delineamento em blocos casualizados com 6 tratamentos e 4 repetições. Os tratamentos (T) foram: T1 - testemunha; T2 - dimetomorfe + clorotalonil (valores de severidade da doença $(\mathrm{VSD}=10)+$ metiram; T3 - metalaxil-M + clorotalonil $(\mathrm{VSD}=10)+$ metiram (o metiram foi aplicado somente na semana onde o VSD não atingiu o valor requerido para o tratamento); T4 - calendário fixo: dimetomorfe + clorotalonil, mancozeb, metalaxil-M + clorotalonil e clorotalonil, alternados semanalmente; T5 - silicato de potássio (5 g/L) e T6 silicato de potássio $(15 \mathrm{~g} / \mathrm{L})$. A severidade foi avaliada utilizando-se uma escala descritiva variando de 0 a $100 \%$. A severidade final foi: 100; 2,6; 12,3; 5,5; 97,6 e $96 \%$, respectivamente, nos tratamentos T1, T2, T3, T4, T5 e T6. A severidade foi em média, $93 \%$ menor nos tratamentos que receberam aplicações de fungicidas em relação a testemunha. Dentre os tratamentos que empregaram sistema de previsão o 2 apresentou melhor resultado do que o 3 . O tratamento 2 apresentou eficiência comparável ao calendário semanal (tratamento 4), apresentando produtividades de 62.103,73 e 52.473,33 kg/ha, respectivamente, sendo superiores aos demais tratamentos. Aplicações de silicato de potássio nas duas doses testadas não diferiram significativamente da testemunha, indicando a ineficiência do produto em controlar a requeima.

Palavras-chave adicionais: manejo integrado, Phytophthora infestans, sistema de previsão.

\begin{abstract}
Control of late blight in industrial tomato with fungicide and potassium silicate

The aim of this study was to test the effect of fungicides and potassium silicate sprays on the control of late blight (Phytophthora infestans) of industrial tomato. The fungicides were applied according to the Wallin forecast system (FS) and on the weekly calendar. The experiment was carried out in a completely randomized block design with six treatments and four replications. The treatments (T) were: T1 - control; T2 - dimethomorph + chlorothalonil (disease severity values - DSV $=10)+$ metiram; T3 - metalaxyl-M + chlorothalonil (DSV = 10) + metiram (metiram was sprayed weekly when the DSV did not reach the required value for the treatment); T4 - calendar: dimethomorph + chlorothalonil, mancozeb, metalaxyl-M + chlorothalonil and chlorothalonil, alternated weekly; T5 and T6 - potassium silicate (5 and $15 \mathrm{~g} / \mathrm{L})$, respectively. The severity of late blight was evaluated according to a scale from 0 to $100 \%$. The final disease severity was $100 ; 2.6 ; 12.3 ; 5.5 ; 97.6$ and $96 \%$, respectively, on the treatments T1, T2, T3, T4, T5 and T6. Disease severity was $93 \%$, less on the treatments that received the application of fungicides compared to the control. The FS (treatment 2) showed better results than treatment 3 . The treatment 2, based on the FS, showed efficiency comparable to the weekly calendar (treatment 4) with yield of 62.103,73 and 52.473,33 kg/ha, respectively. These yields were superior compared to the other treatments. The applications of potassium silicate did not differ from the control. This indicates the inefficiency of this product in the control of late blight.
\end{abstract}

Additional keywords: integrated disease management, Phytophthora infestans, disease forecast.

O tomateiro (Lycopersicon esculentum Mill.) industrial é considerado uma das culturas de grande importância para as regiões Centro-Oeste e Sudeste devido a sua utilização na indústria de extrato de polpa (Camargo Filho \& Mazzei, 1997; Silva \& Giordano, 2000). Entretanto, inúmeros fatores vêm limitando a produção de tomate industrial no Brasil, sendo as doenças um dos mais importantes por reduzirem a produtividade e a qualidade dos frutos. Dentre as doenças que atacam o tomateiro industrial, a requeima, causada por Phytophthora infestans (Mont.) de Bary, é a mais destrutiva, podendo comprometer todo o campo de produção em poucos dias (Stevenson, 1983;
Lopes \& Santos, 1994). A requeima ocorre em praticamente todos os locais onde o tomate é cultivado, sendo mais severa em períodos frios e úmidos. Essa doença é favorecida por alta umidade relativa (neblina, chuva fina, orvalho e ou irrigação freqüente) e temperatura variando de 12 a $20^{\circ} \mathrm{C}$ (Fohner et al., 1984). A requeima também pode ocorrer em regiões de clima quente, desde que as noites sejam frias. Em temperaturas acima de $30^{\circ} \mathrm{C}$, a requeima dificilmente ocorre, mas o patógeno permanece nos restos culturais por cerca de 45 a 60 dias e pode provocar danos assim que as condições climáticas tornarem-se favoráveis (Lopes \& Santos, 1994). Os sintomas da requeima ocorrem nas folhas, hastes, frutos e 
pecíolos do tomateiro apresentando um aspecto semelhante à queima (Kurozawa \& Pavan, 1997).

Várias medidas têm sido estudadas visando tornar a cultura do tomateiro mais rentável ao produtor, além da otimização do uso de fungicidas para o controle da doença. Dentre essas medidas, tem-se destacado o emprego de sistemas de previsão e o uso de produtos alternativos.

Diante da escassez de trabalhos visando o controle da requeima em tomateiro industrial, principalmente com o uso de sistemas de previsão, este trabalho teve como objetivo avaliar a viabilidade do uso do modelo de previsão proposto por Wallin (1962) com modificação e o efeito da aplicação foliar de silicato de potássio, no controle da requeima do tomateiro industrial.

Foi conduzido um experimento no período de setembro a dezembro de 2004 no campo experimental do Departamento de Fitopatologia da Universidade Federal de Viçosa. Utilizou-se o híbrido de tomate industrial $\mathrm{H}$ $7155 \mathrm{~N}$ altamente susceptível à requeima. O delineamento experimental foi em blocos casualizados com seis tratamentos e quatro repetições. $\mathrm{O}$ espaçamento das plantas nas parcelas experimentais foi de $0,30 \times 1,0 \mathrm{~m}$. Cada parcela foi constituída por 4 fileiras contendo 32 plantas, sendo 16 plantas úteis.

Os tratamentos foram constituídos da aplicação de fungicidas sistêmi $750 \mathrm{~g} / \mathrm{kg}$ de i.a. na dose $2,0 \mathrm{~kg} / \mathrm{ha}$ ). O silicato de potássio (Fertisil ${ }^{\circledR}$, INEOS Silicas Ltda) tem $13 \%$ de $\mathrm{K}_{2} \mathrm{O}$, $26,59 \%$ de $\mathrm{SiO}_{2}$ e menos de $0,5 \%$ de $\mathrm{Na}_{2} \mathrm{O}$.

Os valores de severidade da doença (VSD) foram fornecidos pelo aparelho COLPAN 40 com base na temperatura média e horas de molhamento foliar diário. Os tratamentos ( $\mathrm{T}$ ) utilizados nesse estudo foram: $\mathrm{T} 1$ - testemunha (sem aplicação de silicato de potássio e de fungicida); T2 - dimetomorfe + clorotalonil $(\mathrm{VSD}=10)$ + metiram; T3 - metalaxil-M + clorotalonil $(\mathrm{VSD}=10)+$ metiram (o fungicida protetor metiram foi aplicado somente na semana onde o VSD não atingiu o valor requerido para o tratamento); T4- calendário fixo: dimetomorfe + clorotalonil, mancozeb, metalaxil-M + clorotalonil e clorotalonil, alternados semanalmente; T5 - silicato de potássio $(5 \mathrm{~g} / \mathrm{L})$ e T6 - silicato de potássio $(15 \mathrm{~g} / \mathrm{L})$. O silicato de potássio foi aplicado aos 55, 60, 65 e 70 dias após o transplante das mudas de tomate para as parcelas experimentais. As pulverizações foram realizadas empregando-se pulverizador costal manual de 20 litros com bico cônico gastando-se um volume de calda de $1000 \mathrm{~L} / \mathrm{ha}$.

A severidade da requeima em cada parcela experimental foi avaliada a partir do surgimento dos primeiros sintomas da doença nas folhas, utilizando-se uma escala descritiva de notas de 0 a $100 \%$ de severidade adaptada de James (1971). Com isso foi estimada a severidade de cada parcela, sendo avaliadas todas as folhas de cada planta. Notas intermediárias na escala foram utilizadas quando necessário. As avaliações foram feitas dos 55 aos 86 dias após o transplante das mudas com intervalos de 5 a 8 dias. Os valores obtidos ao longo das avaliações foram utilizados para calcular a área abaixo da curva do progresso da requeima (AACPR) conforme proposto por Shaner \& Finney (1977). Os valores da AACPR foram padronizados dividindo-se cada valor pelo número de dias da epidemia.

A temperatura média diária durante o experimento variou de 16,1 a $25,6{ }^{\circ} \mathrm{C}$, com média de 13 horas de molhamento foliar durante a epidemia da requeima. O molhamento foliar variou de 5 a 24 horas. Apesar da duração do molhamento foliar ter sido favorável ao progresso da requeima, as condições climáticas não foram muito favoráveis durante todo período de realização do experimento, porque houve dias em que a temperatura média diária ultrapassou 20 ${ }^{\circ} \mathrm{C}$, fazendo com que o progresso da epidemia da requeima fosse diminuído. Durante todo experimento, houve uma precipitação de $365 \mathrm{~mm}$ em até 7 dias consecutivos, mas ocorrência de dias com chuvas de baixa intensidade.

As curvas de progresso da requeima para os diferentes tratamentos utilizados nesse estudo encontramse representadas na Figura 1. Nos tratamentos 2, 3 e 4, os quais basearam no sistema de previsão e calendário com fungicidas, houve baixo progresso da requeima, com valores de severidade final de 2,$7 ; 12,3$ e $5,5 \%$, respectivamente, comparado aos demais tratamentos. Já nos tratamentos $1,5 \mathrm{e}$ 6 , o progresso da requeima foi maior, com severidade final de $100,97,8$ e 96,0 \%, respectivamente. A Figura 2 e a Tabela 1 representam, respectivamente, a AACPR e a produtividade para os diferentes tratamentos. O tratamento 1 (testemunha) apresentou AACPR de 67 e produtividade de $40 \mathrm{~kg} / \mathrm{ha}$ que foram estatisticamente inferiores comparado aos tratamentos 2,3 e 4 . Os tratamentos 2 e 4 apresentaram controle mais eficiente da requeima, isto devido a produtividades estatisticamente superiores $(62.103,73$ e $52.473,33 \mathrm{~kg} / \mathrm{ha})$ comparado aos demais tratamentos, aos baixos valores de severidade final $(2,7$ e $5,5 \%)$ e a menores AACPRs $(1,7$ e 3,7 ), respectivamente. O tratamento 3 , apesar de ter apresentado AACPR de 6,7, que não diferiu estatisticamente dos tratamentos 2 e 4, não apresentou a melhor eficiência, devido ao valor de severidade final ser um pouco maior que o

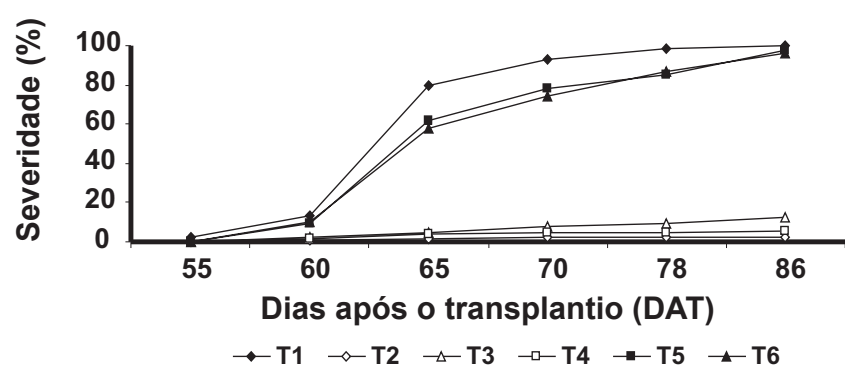

FIG. 1 - Curvas de progresso da requeima para os diferentes tratamentos. Tratamentos: T1 - testemunha (sem aplicação de silicato de potássio e de fungicida); T2 - dimetomorfe + clorotalonil $(\mathrm{VSD}=10)+$ metiram; T3 - metalaxil-M + clorotalonil $(\mathrm{VSD}=$ 10) + metiram; T4 - calendário fixo: dimetomorfe + clorotalonil, mancozeb, metalaxil-M + clorotalonil, clorotalonil; T5 - silicato de potássio $(5 \mathrm{~g} / \mathrm{L})$ e T6 - silicato de potássio $(15 \mathrm{~g} / \mathrm{L})$. 


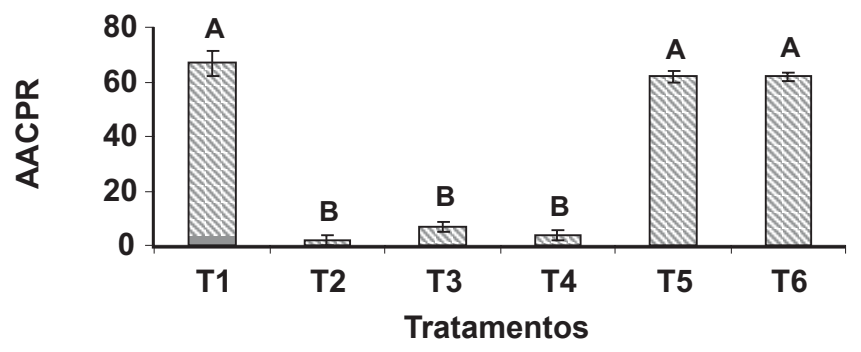

FIG. 2 - Áreas Abaixo das Curvas de Progresso da Requeima (AACPR) para os diferentes tratamentos. Médias seguidas pela mesma letra não diferem entre si pelo teste de Tukey, ao nível de 5\% de probabilidade. Tratamentos: T1 - testemunha (sem aplicação de silicato de potássio e de fungicidas); T2 - dimetomorfe + clorotalonil $(\mathrm{VSD}=10)+$ metiram; T3 - metalaxil-M + clorotalonil $(\mathrm{VSD}=$ 10) + metiram; T4- calendário fixo: dimetomorfe + clorotalonil, mancozeb, metalaxil-M + clorotalonil, clorotalonil; T5 - silicato de potássio $(5 \mathrm{~g} / \mathrm{L})$ e T6- silicato de potássio (15 g/L). Os valores apresentados correspondem a média de 4 repetições e as barras para cada coluna representam o desvio padrão da média.

TABELA 1 - Produtividade e número de pulverizações com fungicidas sistêmicos, fungicidas protetores e com silicato de potássio nos diferentes tratamentos visando o controle da requeima do tomateiro industrial

\begin{tabular}{|c|c|c|c|c|}
\hline \multirow[b]{2}{*}{ Tratamentos } & \multicolumn{3}{|c|}{ Número de pulverizações de cada produto } & \multirow[b]{2}{*}{$\begin{array}{l}\text { Produtividade } \\
\text { (kg/ha) }\end{array}$} \\
\hline & $\begin{array}{r}\text { Fungicida } \\
\text { sistêmico } \\
\end{array}$ & $\begin{array}{c}\text { Fungicida } \\
\text { protetor }\end{array}$ & $\begin{array}{c}\text { Silicato } \\
\text { de Potássio }\end{array}$ & \\
\hline $1^{11}$ & - & - & - & $40,00^{12}$ \\
\hline 2 & 4 & 5 & - & $62.103,73 \mathrm{c}$ \\
\hline 3 & 4 & 5 & - & $36.607,86 \mathrm{~b}$ \\
\hline 4 & 5 & 4 & - & $52.473,33 \mathrm{c}$ \\
\hline 5 & - & - & 4 & 100,05 \\
\hline 6 & - & - & 4 & 112,02 \\
\hline C.V. $(\%)$ & & & & 20,1 \\
\hline \multicolumn{5}{|c|}{$\begin{array}{l}-=\text { nenhuma pulverização foi realizada. } \\
\text { e de fungatamentos: T1 - testemunha (sem aplicação de silicato de potássio } \\
\text { metiram; T3 - metalaxil-M + clorotalonil (VSD = } 10)+ \text { metiram; T4- } \\
\text { calendário fixo: dimetomorfe + clorotalonil, mancozeb, metalaxil-M } \\
\text { + clorotalonil , clorotalonil; T5 - silicato de potássio }(5 \mathrm{~g} / 1) \text { e T6- } \\
\text { silicato de potássio }(15 \mathrm{~g} / 1) \text {. } \\
1{ }^{2} \text { Média de } 4 \text { repetições. Médias seguidas por pelo menos uma mesma } \\
\text { letra não diferem entre si pelo teste de Tukey ao nível de } 5 \% \text { de } \\
\text { probabilidade. }\end{array}$} \\
\hline
\end{tabular}

tratamentos 2 e 4 e a produtividade ter sido estatisticamente inferior aos tratamentos 2 e 4 . O valor de severidade final do tratamento 3 foi de $12,3 \%$, que em média é de três vezes maior que os valores de severidade final dos tratamentos 2 e 4, com isso as plantas do tratamento 3 tiveram uma maior área necrosada pela doença e consequentemente menor área fotossinteticamente ativa, produzindo menor quantidade de fotoassimilados, o que explica a menor produtividade do tratamento 3 comparado aos tratamentos 2 e 4 . Nazareno et al. (1999) alertam quanto a necessidade de atenção quando se analisa apenas a AACPR, isto porque curvas de progresso com um mesmo valor de AACPR podem apresentar diferenças quanto ao tempo inicial, severidade final e à taxa de progresso da doença. Já os tratamentos 5 e 6 , que corresponderam a aplicação de silicato de potássio, não diferiram estatisticamente da testemunha tanto em relação a $\operatorname{AACPR}(62,0$ e 61,2 respectivamente) quanto a produtividade (100,05 e $112,02 \mathrm{~kg} / \mathrm{ha}$, respectivamente), comprovando a ineficiência desses tratamentos no controle da requeima nas condições em que foi conduzido o experimento. Em pepino, melão e abóbora, a aplicação foliar de silicato de potássio nas concentrações de até $17 \mathrm{mM}(1.000 \mathrm{ppm}$ de Si) foi efetiva em reduzir o número de colônias de míldio pulverulento nas folhas (Menzies et al., 1992). Bowen et al. (1992) relataram que a aplicação de silicato de potássio no solo na dose de $1,7 \mathrm{mM}$ de Si não reduziu o número de colônias de míldio pulverulento em folhas de uva, mas a pulverização das folhas com silicato de potássio, na mesma dose, reduziu em mais de 60 \% o número de colônias de míldio pulverulento. Os autores explicaram que a redução na severidade da doença deve-se, em parte, a uma barreira física formada pela polimerização do silicato na superfície foliar que impede a adesão dos propágulos do patógeno; além disso, o movimento lateral do silício e sua deposição dentro da folha impediria a penetração do patógeno nos tecidos da planta.

O tratamento 2, baseado no sistema de previsão de Wallin (1962) com modificações, apresentou o mesmo número de pulverizações que o tratamento 4 que baseouse no calendário semanal de pulverizações. Entretanto, no sistema de previsão houve redução de uma pulverização com fungicida sistêmico comparado ao calendário de pulverização semanal. Os tratamentos 2 e 4 apresentaram produtividade e eficiência semelhantes no controle da requeima (Tabela 1). Resultados semelhantes foram obtidos por Costa et al. (2002), os quais utilizaram o sistema de previsão de Wallin para o controle da requeima da batateira. Segundo esses autores, o uso do sistema de previsão com VSD-14 permitiu reduzir o número de pulverizações com fungicida sistêmico sem que houvesse perda significativa na produção. Costa et al. (2005), em experimento realizado com tomate de mesa, também relataram redução no número de pulverizações com fungicida sistêmico empregando-se VSD de 14-16 em 1998, e um VSD de 11-13 e 14-16 em 1999, obtendo a mesma eficiência do calendário de pulverização semanal no controle da requeima. A redução de uma pulverização com fungicida sistêmico obtida com o uso do sistema de previsão proporciona menor custo de produção, pois os fungicidas sistêmicos são mais caros, além disso há redução de resíduos nos frutos e menor agressão ao meio ambiente. Entretanto, nem sempre se obtém redução do número de pulverizações com o sistema de previsão. Sob condições climáticas muito favoráveis ao progresso da requeima, pode não haver redução do número de pulverizações, podendo em determinados casos, até ocorrer aumento no número de pulverizações (Mizubuti, 1999). Isto foi comprovado em experimento realizado por Duarte et al. (2006), o tratamento 
dimetomorfe + clorotalonil $(\mathrm{VSD}=10)+$ metiram baseado no sistema de previsão foi o mais eficiente, mas não permitiu reduzir o número de pulverizações com fungicida sistêmico em relação ao calendário fixo de pulverização, devido às condições climáticas terem sido muito favoráveis a requeima, entretanto permitiu uma melhor distribuição das pulverizações ao longo do período de cultivo, dado que as mesmas só foram efetuadas quando se tinha condições favoráveis. Apesar do sistema de previsão ter aumentado duas aplicações de fungicida sistêmico, esse aumento é compensado por ter gerado uma produtividade três vezes maior do que a obtida com o calendário fixo de pulverização.

O calendário de pulverização semanal utilizado neste trabalho foi bastante moderado, porque normalmente quando as condições climáticas são muito favoráveis ao progresso da requeima é comum o emprego de duas a três pulverizações por semana. De acordo com os resultados deste trabalho, o emprego do sistema de previsão da requeima em tomateiro industrial utilizando-se dimetomorfe + clorotalonil (VSD =10) + metiram torna-se uma alternativa interessante de controle a ser empregada dentro do contexto do manejo integrado da requeima do tomateiro.

\section{REFERÊNCIAS BIBLIOGRÁFICAS}

BOWEN, P., MENZIES, J., EHRET, D., SAMUELS, L. \& GLASS, A.D.M. Soluble silicon sprays inhibit powdery mildew development on grape leaves. Journal of the American Society for Horticultural Sciense 117:906-912. 1992.

CAMARGO FILHO, W.P. \& MAZZEI, A.R. Mercado mundial de tomate e o mercosul. Informações Econômicas 27:25-38. 1997.

COSTA, R.V., ZAMBOLIM, L., VALE, F.X.R. \& MIZUBUTI, E.S.G. Prediction system fot tomato late blight. Summa Phytopathologica 31:14-20. 2005.

COSTA, R.V., ZAMBOLIM, L., VALE, F.X.R. \& MIZUBUTI, E.S.G. Previsão da requeima da batateira. Fitopatologia Brasileira 27:349-354. 2002.
DUARTE, H.S.S., ZAMBOLIM, L. \& JESUS JUNIOR, W.C. Manejo da requeima do tomateiro empregando sistema de previsão para determinação do momento adequado de pulverização. Anais, $46^{\circ}$ Congresso Brasileiro de Olericultura. Goiânia GO. 2006. pp. 716-719.

FOHNER, G.R., FRY, W.E. \& WHITE, G.B. Computer simulation raises question about timing protecting fungicide application frequency according to potato late blight forecast. Phytopathology 74:1145-1147. 1984.

JAMES, W.C. A manual of assessment keys for plant diseases. Canada. Departament of Agriculture. (Publ.nº 1458). 1971.

KUROZAWA, C. \& PAVAN, M.A. Doenças do tomateiro (Lycopersicon esculentum). In: Kimati, H., Amorim, L., Rezende, J.A. M., Bergamim Filho, A. \& Camargo, L.E.A. (Eds.) Manual de Fitopatologia - Doenças das plantas cultivadas. São Paulo SP. Agronômica Ceres Ltda. 2005. pp. 607-626.

LOPES, C.A. \& SANTOS, J.R.M. Doenças do tomateiro. Brasília: EMPRABA/CNPH, 1994.

MENZIES, J., BOWEN, P., EHRET, D.L. \& GLASS, A.D.M. Foliar applications of potassium silicate reduce severity of powdery mildew on cucumber, muskmelon, and zucchini squash. Journal of the American Society for Horticultural Sciense 117:902-905. 1992.

MIZUBUTI, E.S.G. Sistemas de previsão de doenças de plantas: uma ferramenta útil? In: Zambolim, L. (Ed.) Manejo Integrado de Doenças e Pragas. Visconde do Rio Branco MG. Suprema Gráfica e Editora. 1999. pp. 42-46.

NAZARENO, N.R.X., SCOTTI, C.A., MAFIOLETTI, R.L. \& BOSCHETTO, N. Controle da requeima da batata através do monitoramento das variáveis climáticas. Fitopatologia Brasileira 24:170-174. 1999.

SHANER, G. \& FINNEY, R.E. The effect of nitrogen fertilization on the expression of slow-mildewing resistance in Knox wheat. Phytopathology 67:1051-1056. 1977.

SILVA, J.B.C. \& GIORDANO, L.B. Produção mundial e nacional. In: Silva, J.B.C. \& Giordano, L.B. (Eds.) Tomate para processamento industrial. Brasília DF. EMBRAPA Hortaliças. 2000. pp. 8-11.

STEVENSON, W.R. An integrated program for managing potato late blight. Plant Disease 67:1047-1048. 1983.

WALLIN, J.R. Summary of recent progress in predicting late blight epidemics in United States and Canada. American Potato Journal 39:306-312. 1962. 